\title{
EMBLEMÁTICA, MNEMOTECNIA Y EL ARTE DE NARRAR EN EL PEREGRINO EN SU PATRIA DE LOPE DE VEGA
}

\author{
EMBLEMS, MNEMONICS AND STORY TELLING IN LOPE DE VEGA'S \\ EL PEREGRINO EN SU PATRIA
}

Claudia Mesa Higuera

Moravian College

\begin{abstract}
This essay examines an aspect of Lope de Vega's iconographic program in El peregrino en su patria by focusing on the interpolated tale of Everardo, a Christian knight who has been confined to a prison cell that is painted with "hieroglyphs and verses». The episode combines rhetorical and dialectical aspects of memory and establishes a connection between artificial memory systems, emblems, secular meditational practices, and storytelling. Everardo's tale displays a mnemonic intentionality that connects it with the artificial systems of memory that were developed in classical antiquity and were later used as prototypes during the early modern period. The episode not only emphasizes the importance of emblems as stimuli to assist memory but also stresses the narrative potential of the emblem and its capacity to produce a sequential dual narrative. This dual narrative consists of the ekphrastic description of the emblems by the narrator and the understanding of Everardo's own past through his interpretation of the emblematic images.
\end{abstract}

KEYWORDS: emblems, mnemonics, sequential narratives, El peregrino en su patria, Lope de Vega.

RESUMEN: Este ensayo examina un aspecto del programa iconográfico del Peregrino en su patria de Lope de Vega al enfocarse en el relato intercalado de Everardo, un caballero preso en una celda cuyas paredes se encuentran dibujadas con "hieroglíficas y versos». El episodio combina aspectos retóricos y dialécticos de la memoria y propicia la conexión entre sistemas de memoria artificial, emblemas, prácticas meditativas de corte secular y estrategias narrativas. Propongo que el relato de Everardo puede entenderse a la luz de cierta intencionalidad mnemónica, que lo vincula con los sistemas de memoria artificial desarrollados en la antigüedad clásica y posteriormente usados como prototipos durante la temprana modernidad. Este episodio no sólo destaca la importancia de la imagen como estímulo para la memoria sino que también genera una narración secuencial a dos voces donde los procesos mentales asociados con la memoria retórica y la dialéctica encuentran resolución.

PALABRAS CLAVES: emblemas, mnemotecnia, narración secuencial, El peregrino en su patria, Lope de Vega.

Fecha de recepción: 1-12-2014 / Fecha de aceptación: 13-8-2015 
El peregrino en su patria, la primera y única novela bizantina de Lope, se publica en Sevilla en 1604 en la imprenta de Clemente Hidalgo. Se reedita siete veces entre 1604 y 1608 y se traduce tanto al francés como al inglés en 1614 y en 1621, respectivamente. Sus numerosas ediciones demuestran la acogida que tuvo esta obra entre los lectores. Lope tenía alrededor de 42 años y había alcanzado tremendo éxito entre las masas que recibían con entusiasmo sus comedias. «El monstruo de naturaleza, el gran Lope de Vega» (93)-como lo llamaba Cervantes- era ya por ese entonces un autor popular y prolífico, aclamado por el pueblo y odiado entre sus detractores. Éstos, liderados por don Luis de Góngora y sus seguidores lo tildaban de ignorante ya que había transgredido los principios clásicos de la composición dramática y advocaba, al menos en teoría, por dale "gusto al pueblo, aunque se ahorque el arte» (cit. en Samson, 2008: 235). El prólogo que acompaña la edición princeps de El peregrino deja en claro el alcance de su obra. Incluye una lista autorizada de sus comedias que hasta entonces llegaba a los 219 títulos. ${ }^{1}$ Para la edición de 1618, Lope apunta 228 títulos más. Estas listas no incluían piezas religiosas, poesía ni prosa narrativa.

En la obra es notable la presencia de un complejo programa iconográfico en el que sobresale una celda decorada con jeroglíficos, galerías de pinturas seculares y religiosas, edificios sacros adornados con imágenes, cuatro autos sacramentales y ejemplos de arquitectura efímera dispuestos en las calles de Zaragoza para celebrar la dinastía Habsburgo. Entre las piezas preliminares, El peregrino ostenta el retrato de Lope con las 19 torres del escudo de Bernardo del Carpio, que delatan la tan controvertida como falsa genealogía de su autor ${ }^{2}$, y un revelador frontispicio que sugiere los

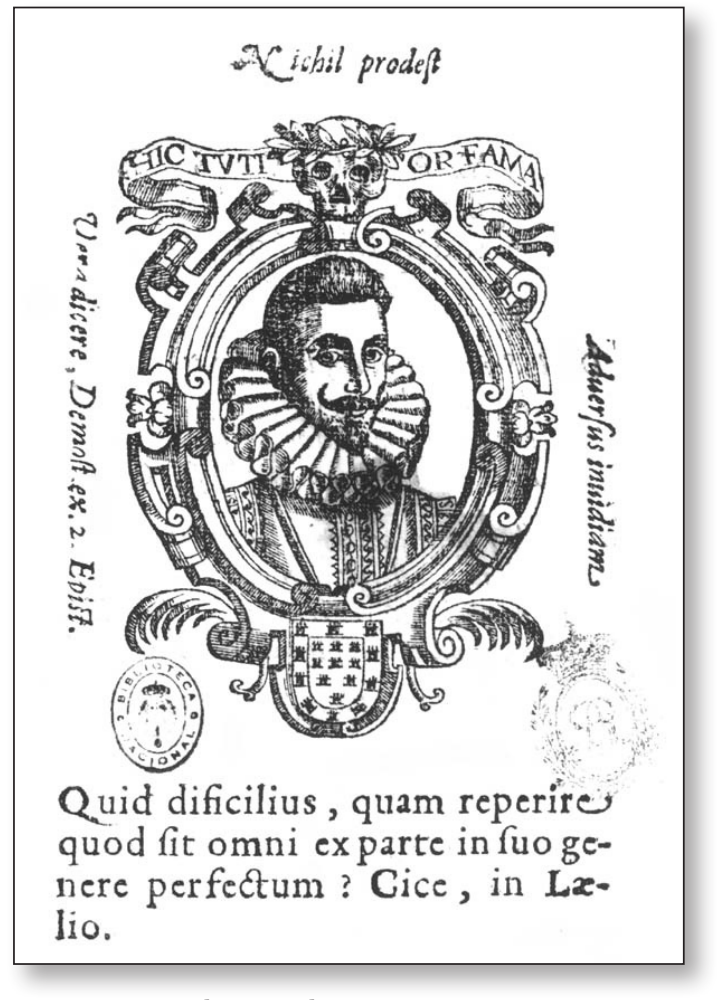

Fig. 1. Retrato de Lope de Vega.

sentimientos encontrados del Fénix por la época en que se publica la novela [figs. 1 y 2]. La parte superior del frontispicio la domina la figura de Pegaso superpuesto al lema Seianus michi Pegasus (La mala fortuna ha sido una fuente de inspiración para mí). ${ }^{3} \mathrm{Al}$ caballo alado lo sostienen dos columnas. Dentro de la primera se encuentra La Envidia que intenta traspasar el corazón que lleva en la mano con una daga. En la segunda, se aprecia la estatua del Peregrino cuyos atributos lo vinculan con la representación de Exilio que registra Ripa en su Iconologia (González Rovira, 2004: 147). Allí se pinta un hombre en hábito de peregrino que tiene en la derecha un bordón y en la izquierda un halcón [fig. 3]. ${ }^{4}$

1. Sobre de la importancia del prólogo ver Giuliani.

2. Acerca del escudo falso de Lope ver McCready, 1957

3. Kossoff también traduce este lema como «El caballo de Seius ha sido un Pegaso para mí» (335).

4. Sobre el frontispicio como el retrato de Lope ver Avalle Arce, González Rovira y Samson. 


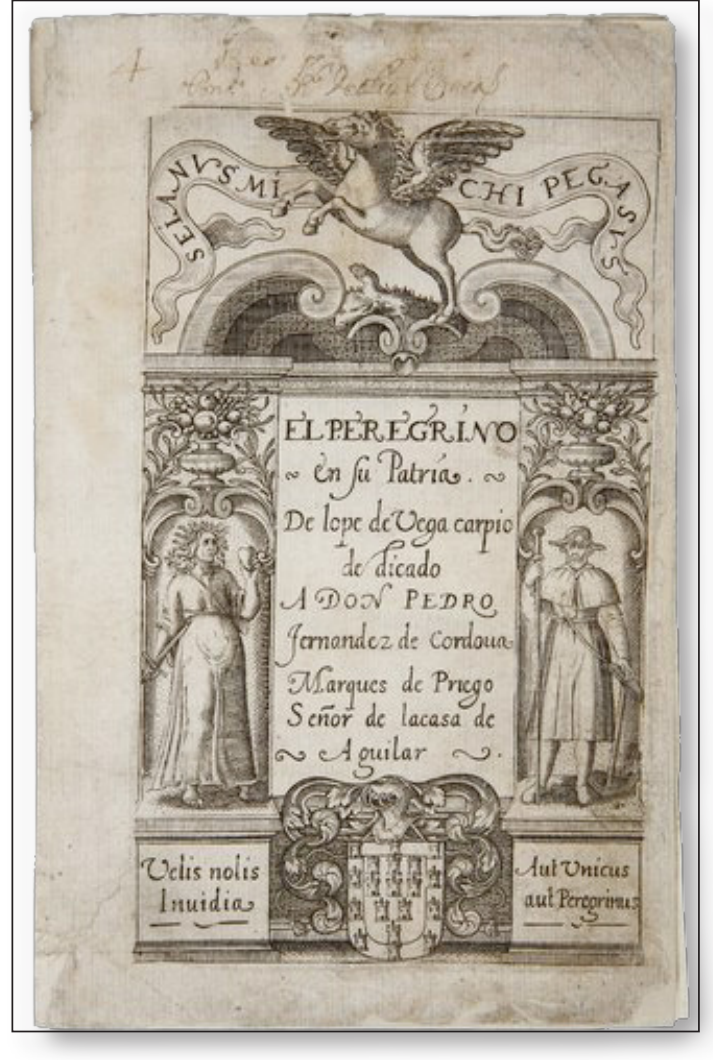

Fig. 2. Frontispicio de la edición de El peregrino en su patria (1604).

Dichas estatuas y sus correspondientes lemas -Velis nolis InvidialAut unicus aut peregrinus (Quieras o no quieras, Envidia, Lope de Vega es único o peregrino)- dan cuenta de la soberbia y evidente incomodidad del autor, quien a través de esta composición, pone de relieve tanto la singularidad de su ingenio como la adversidad de un destino marcado por la envidia y el resentimiento. Como si se tratara de una acotación al frontispicio, en la Jerusalén conquistada Lope escribe: "Yo siempre, de la envidia perseguido,/extranjero en mi patria y desterrado» (cit. en González Rovira, 2004: 147).

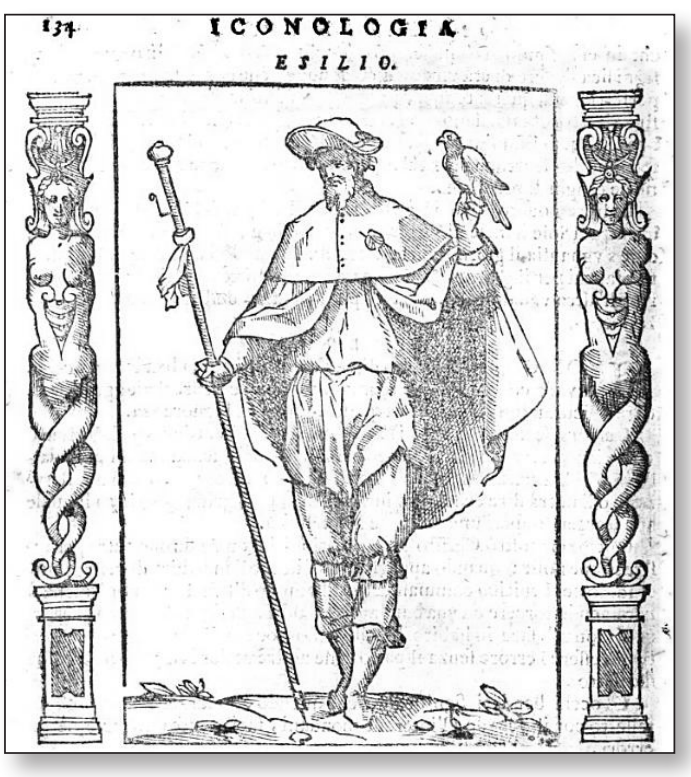

Fig. 3. Cesare Ripa, Iconología. Representación de «Escilio" [Exilio].

En este ensayo examino una faceta del programa iconográfico de El peregrino en su patria que se enfoca en el relato intercalado de Everardo, un caballero viejo confinado a una celda decorada con jeroglíficos y versos (441). El episodio combina aspectos retóricos y dialécticos de la memoria y propicia la conexión entre sistemas de memoria artificial, emblemas, estrategias narrativas y prácticas meditativas de corte secular, que subrayan la importancia de la imagen como estímulo para el discurso y la meditación. ${ }^{5}$ Propongo que el relato de Everardo puede entenderse a la luz de cierta intencionalidad mnemónica, ${ }^{6}$ que lo vincula con los sistemas de memoria artificiosa desarrollados en la antigüedad clásica y usados como prototipos durante la temprana modernidad. Concebidos como ejercicios retóricos y de persuasión entre oradores, estas técnicas mentales del recuerdo privilegian la interdependencia entre lugares e imágenes para recordar ideas

5. La distinción entre sistemas retóricos y dialécticos de la memoria viene de Richards.

6. Sobre el vínculo entre emblemática y mnemotecnia así como de la relación entre memoria y melancolía ver Egido.

IMAGO, NÚM. 7, 2015, 87-96 
y conceptos. Sugiero que el relato de Everardo presenta variaciones y adaptaciones al prototipo clásico, en tanto que hace uso de técnicas asociadas con los sistemas de memoria artificial, e introduce elementos emblemáticos que permiten construir una narración secuencial a partir de la interacción entre la imagen y la palabra. ${ }^{7}$

En El peregrino Lope toma como modelo el género del romance griego ${ }^{8}$-Las etiópicas de Heliodoro y Leucipa y Clitofonte de Aquiles Tacio- para relatar los obstáculos por los que pasan Pánfilo y Nise antes de que puedan unirse en matrimonio. Se trata de una novela robusta en más de un sentido. Por una parte ocupa más de 300 folios distribuidos a lo largo de cinco libros. Siguiendo la tradición bizantina, la novela comienza in medias res; inicia con el naufragio de Pánfilo y desemboca en episodios de celos, intrigas, locura, robos, asesinatos, encarcelamientos y esclavitud. Por otra parte la multiplicidad de eventos se refleja también en la textura figurativa de la prosa, donde los elementos visuales de carácter simbólico suponen un desafío a la capacidad interpretativa del lector (Checa, 2002: 99). Si bien la peregrinación de Pánfilo es, como la califica González Rovira, "amorosa, religiosa y existencial» (146), asimismo está configurada a partir de lo que podría denominarse una compleja retórica de la imagen. Los lectores adquieren la capacidad de ver y visitar espacios y lugares literarios a través de la voz del narrador. Uno de estos lugares es la celda de Everardo, un caballero preso, quien desde el comienzo le ofrece su amistad al peregrino errante.

El programa emblemático que se encuentra dispuesto en la celda está mediatizado, al menos en un principio, por la voz de del narrador. Deffis de Calvo examina los pasajes emblemáticos a partir del orden en que son presentados ante el lector y de la función que tienen dentro de una narrativa que subraya el acto de mirar (1993: 22). El narrador explica que tan pronto como Pánfilo entra en la habitación, nota que las paredes están cubiertas de «hieroglíficas y versos» (441). Aunque estén dibujados con carbón, su presencia, sentido y artificio le indican que "no era el dueño ignorante» (441). Una vez que Pánfilo, el peregrino, le cuenta sus desventuras a Everardo, éste comienza su relato. Pero antes, el narrador presenta ante los lectores una serie de «emblemas nudos», es decir de emblemas descritos pero no pintados, que los lectores de la novela de Lope visualizan a través de las palabras del narrador. Las imágenes se generan por medio de descripciones ekfrásticas que ofrecen un anticipo icónico-verbal de la historia. Por medio de ellas, es posible establecer conjeturas acerca de la naturaleza del relato antes de que Everardo no sólo vuelva a organizar las imágenes sino que también fije su significado a través de la secuencia narrativa que construye. El programa de la celda está compuesto por siete emblemas descritos por el narrador en el siguiente orden:

1. Dibujado en la parte más prominente del aposento, se encuentra el retrato de un hombre joven. Debajo de éste un verso tomado de la Eneida (libro 2, versos 269-270): «Ante sus ojos Héctor triste en sueños" (441). ${ }^{9}$

2. En otro lugar, un corazón alado vuela tras la representación alegórica de la muerte. Como en el caso anterior, el

7. Carruthers señala que es más útil pensar en memoria, no como un proceso mecánico sino más bien como un arte de la composición, que involucra y fomenta facultades imaginativas y creativas (9). Para sistemas de la memoria en el contexto de la temprana modernidad en España ver Rodríguez de la Flor.

8. Sobre del discutido debate acerca del apropiado género literario en el que debe situarse la obra, o novela bizantina o romance griego, ver Lara Garrido y Avalle Arce.

9. La proveniencia de los motes en este relato ha sido identificada tanto por Deffis de Calvo como por Avalle-Arce en su edición de El peregrino. La cursiva de los emblemas, se encuentra en el original de Lope. 
lema proviene de la Eneida (libro XI, verso 170): "Muerto Palante» (441).

3. Cerca del corazón alado, se aprecia una pintura de Prometeo encadenado a la roca caucásica. A su lado, un águila se alimenta constantemente de sus entrañas. La letra que acompaña a la imagen, se halla en Metamorfosis (libro 1, versos 76-78): "¡Oh cuánta pena es vivir/vida enojosa y forzada,/y cuando la muerte agrada, ser imposible morir!» (441).

4. El cuarto emblema enseña a un joven que sin éxito trata de deshacerse de «una carga de memorias» en el río del Olvido. El lema proviene de De rerum natura (III, 1002) de Lucrecio y alude a los trabajos de Sísifo: "Vuelve a caer, cuando al estremo llega» (441).

5. El quinto emblema está dibujado en una puerta. La pictura muestra la cabeza de Orfeo y su lira flotando sobre las aguas del río Estrimón. El mote está tomado de los Epigrammata (1554) de Etienne Forcadel y dice: "Aquí lloraron selvas, fieras y áspides" (442).

6. El sexto emblema enseña el cuerpo muerto de una mujer atravesada por una espada. La inscriptio proviene de Julio César Escalígero en su Poemata omnia (1621) y declara: "¿No basta, griegos, que venzáis los hombres?» (442).

7. El último y séptimo emblema se ubica en la «distancia desde el marco de la ventana hasta el techo" (442). La pictura muestra a Mercurio mientras intenta que Argos, el gigante de los cien ojos, se adormezca. Debajo de la imagen el epigrama de Tito Vespasiano Strozzi tomado del Eroticon libri sexti (1513) sirve de lema: "Amor sutil al más celoso engaña» (442). ${ }^{10}$

El programa emblemático de Everardo puede entenderse como una adaptación de las técnicas clásicas empleadas en los sistemas de memoria artificial y consignadas en la Rethorica ad Herennium (c. 100 AC.) y en el De oratore de Cicerón (55 AC). Ambos documentos subrayan la importancia de contraponer imágenes individuales sobre lugares o trasfondos; Constat igitur artificiosa memoria ex locis et imaginibus (Yates, 1966: 6). Los lugares son estancias que pueden ser recordados fácilmente por el orador: «Una casa, el espacio interno de una columna, un recoveco, un arco" (Ad Herennium 44; mi traducción). Por otra parte, las imágenes son «marcas» o "simulacra» que representan las palabras, las cosas o los conceptos que se quieren recordar y verbalmente reproducir, teniendo en cuenta un orden específico. Dado que las imágenes llegan hasta nosotros a través del sentido de la vista-según Cicerón el más agudo de todos-éstas deben ser «fuertes y agudas y apropiadas para ser recordadas" (Ad Herennium 46). Por ello, entre más memorables sean las imágenes, más fácil le será al orador retener la información previamente archivada en las locaciones y llevar a cabo la pronunciación del discurso elaborado a partir de ellas.

En la historia se puede apreciar la estructura básica recomendada en las artes de la memoria desarrolladas por los clásicos. Su celda es la estructura arquitectónica en la que se encuentran dispuestas las imáge-

\footnotetext{
10. Limito mi discusión a explorar la relación entre construcciones emblemáticas y sistemas de memoria artificial pero no examino -excepto en algunas notas- las posibles correspondencias entre los emblemas de Everardo y motivos específicos tomados de libros de emblemas. Dixon anota que el conocimiento de la emblemática de Lope proviene de los siguientes autores y obras: Emblematum liber (1531) de Andrea Alciato, Picta poesis (1552) de Barthélemy Aneau, Symbolorum et emblematum centuriae quatuor (1605) de Joachim Camerarius y Hieroglyphica (1575) de Piero Valeriano. Entre los emblematistas españoles, Lope se encuentra familiarizado con los Emblemas morales (1589) de Juan de Horozco, las Emblemas moralizadas (1599) de Hernando de Soto y los Emblemas morales (1610) de Sebastián de Covarrubias Horozco.
} 
nes, un espacio familiar donde se aprecia la representación visual de sus penas. A partir de la narración, es posible inferir que el orden y arreglo de las imágenes es importante, noción que como se sabe, también figura en las fuentes clásicas. Por ejemplo, antes de que Everardo cuente su historia, los lectores pueden concluir que la trama gira alrededor del hombre joven que aparece en el retrato ya que ocupa el espacio más prominente de la habitación. Algo similar ocurre con el emblema de Argos y Mercurio. Ubicado en el espacio entre el marco de la ventana y el techo, el retrato llama la atención ya que refuerza el tema de los celos y la vana vigilancia que como se verá, tiene un papel significativo en la historia.

A continuación me gustaría comentar otro aspecto del programa de Everardo en conjunción con el uso de emblemas como ayudas para la memoria. ${ }^{11}$ Cabe mencionar que los emblemas dispuestos en las paredes de la prisión no se ajustan con exactitud a las características particulares del emblema triplex, que en su forma canónica privilegia la interrelación entre el lema, la pictura y el epigrama. Aunque los emblemas de Everardo presentan un lema y una imagen, el epigrama que hace aparente la conexión entre el lema y la figura, está ausente o mejor, aparece incorporado en el relato. En ese sentido, el relato que conocemos a través de Everardo, funciona a la vez como epigrama y comentario en prosa. La historia contada por el caballero viejo se transforma en la subscriptio que clarifica, estabiliza y le da sentido a la relación entre los lemas y las figuras. Asimismo, los emblemas dispuestos en la celda revelan la capacidad de Everardo de sintetizar los acontecimientos de su vida pasada en forma de metáforas visuales, que le facilitan la expresión verbal de las mismas. En suma, el programa emblemáti- co funciona como un sistema de memoria artificial en el que los elementos icónicos y lingüísticos condensan el significado y contribuyen a la expresión de aquello que Everardo ve representado en el interior de su aposento.

Tras la descripción inicial de los emblemas por parte del narrador, Everardo pasa a relatar su propia historia. Se trata de un triángulo amoroso entre Mireno, el mejor amigo de Everardo, Lucrecia, la esposa adúltera, y Telémaco, el marido celoso que en vano cuida de ella. En el relato, Everardo es el amigo fiel que sin mucho éxito le advierte a Mireno sobre los peligros de la relación con Lucrecia. A pesar de la vigilancia y consejos prudentes de Everardo, el episodio termina con la trágica muerte de los amantes a manos del esposo cornudo, quien asesina a Mireno con un arcabuz y a Lucrecia la atraviesa con una espada. Tras los hechos, Everardo venga a Mireno con la muerte de Telémaco y es así como termina tras las rejas.

Las conexiones entre los eventos ocurridos y las figuras que se encuentran exhibidas en el interior de la celda, se vuelven explícitas a medida que Everardo cuenta la causa de su desgracia. Sin embargo, hay que anotar que el orden en el que recuerda el contenido visual de sus metáforas, difiere del propuesto por el narrador al comienzo del episodio. Por ejemplo, de los siete emblemas presentados inicialmente, solo tres el de la mujer muerta, el emblema de Argos y Mercurio y el de la cabeza de Orfeo- están específicamente relacionados con el curso de los acontecimientos de la historia. El primero nos enseña el cuerpo de Lucrecia mortalmente herido justo después de que los amantes son sorprendidos por Telémaco. El segundo alude al momento en el que Mireno le confiesa a Everardo que, a pesar

11. El uso de emblemas como recursos mnemónicos hace eco a las palabras de Saavedra Fajardo: «Propongo a V. A. la Idea de un Principe Político Cristiano, representada con el buril y con la pluma, para que por los ojos y los oídos (instrumentos del saber) quede más informado el ánimo de V.A. en la sciencia de reinar y sirvan las figuras de memoria artificiosa" (169). 


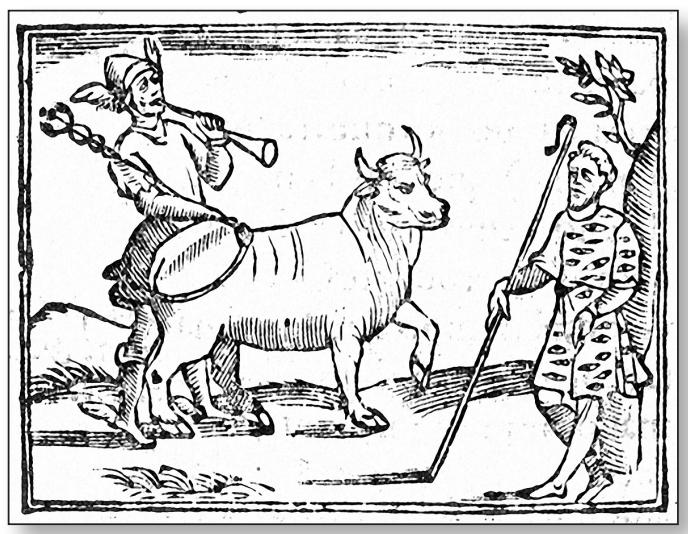

Fig. 4. Hernando de Soto, Emblemas moralizadas. Emblema "Zelotytpus, El vigilante zeloso".

de la constante vigilancia del marido para con su esposa, Lucrecia sucumbe a su pasión y le entrega «el mal guardado tesoro de los cien ojos de Telémaco» (I, 445). En la historia, Telémaco representa a Argos, el pastor celoso, quien aún con sus cien ojos no logra guardar el honor de su mujer. Mireno hace las veces de Mercurio quien con su ligereza y sagacidad consigue evadir a su rival y seducir a Lucrecia [fig. 4]. ${ }^{12}$ El tercero, «aquella cabeza destroncada y la lira de Orfeo" (450), nos habla de la manifestación de duelo de la ciudad entera por la muerte de los amantes, pues no hubo «árbol, animal ni piedra, a quien no enterneciese tan triste caso» (450) [fig. 5]. ${ }^{13}$

Excepto por el retrato de Mireno, que es el foco de la reflexión de Everardo, los tres emblemas restantes se refieren no tanto al transcurso de los acontecimientos, sino más bien a su estado emocional y a los efectos de

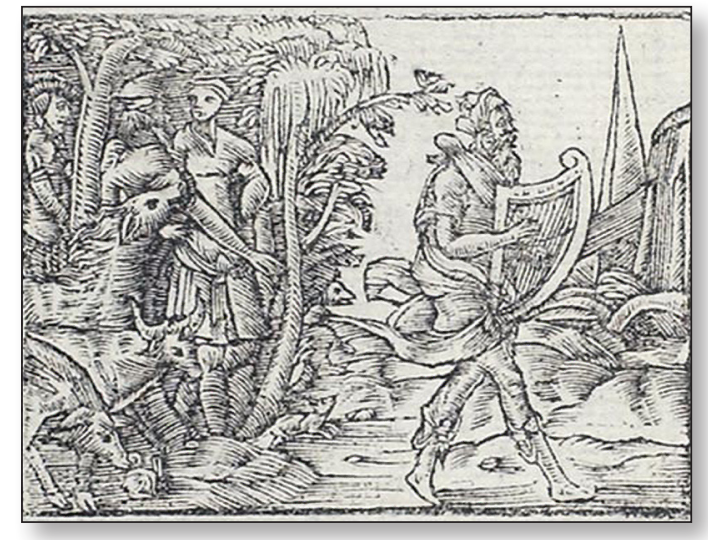

Fig. 5. Pierre Coustau, Pegma. Emblema «In Orpheum».

la tragedia sobre su propia vida. El emblema del corazón alado que vuela sobre un cuerpo, refleja el deseo de Everardo de unirse con su amigo en el más allá: «ha cinco años que vivo deseando la muerte, como te enseña aquel corazón con alas, figura del mío que va volando tras aquella muerte» (450). Asimismo, la inclusión de las figuras de Prometeo [fig. 6] y de Sísifo [fig. 7] en la narración, hace hincapié en el sentimiento de impotencia hacia su propio destino. ${ }^{14}$ Tanto Prometeo como Sísifo subrayan la debilidad del protagonista y sirven como símbolos visuales de la futilidad de su esfuerzo.

El hecho de que Everardo reorganice las imágenes de la celda, a medida que cuenta su historia, concuerda con la idea propuesta por el autor de Ad Herennium, para quien los sistemas de memoria artificial son "la casa del tesoro de las ideas» (43) a partir de los cuales el hablante elige y adapta su discurso

12. Un posible correspondiente emblemático de este pasaje es el emblema de Hernando de Soto, «Zelotytpus: El vigilante zeloso». En el extremo derecho se encuentra Argos recostado sobre un árbol. Lleva una vara en la mano y un vestido cubierto con ojos. A su izquierda, Mercurio, que se distingue por el caduceo, toca un instrumento musical mientras intenta robarle a Argos la vaca de Juno. El comentario del emblema refuerza el sentido que le da Lope: «Es el zelo tan poderoso en el hombre, que totalmente le descompone el juyzio [...]. Esto se verifica bien en los zelosos amantes» (cit. en Bernat Vistarini, 1999: 102).

13. Para emblemas con el motivo de Orfeo ver Pierre Coustau, «In Orpheum».

14. Entre los emblemas asociados con la iconografía de Prometeo se destacan el de Alciato en la traducción de Daza Pinciano, "Que con cuydado se acança la scineçia [ciencia]" así como el de Barthélemy Aneau, "Curiositas fugienda» (Se debe evitar la curiosidad). Para la figura de Sísifo ver Juan Horozco Covarrubias, "Sísifo» [sin lema] y de Aneau, "Interminabilis Humanae Vitae Labor» (Los sufrimientos de la vida humana son interminables).

IMAGO, NÚM. 7, 2015, 87-96 


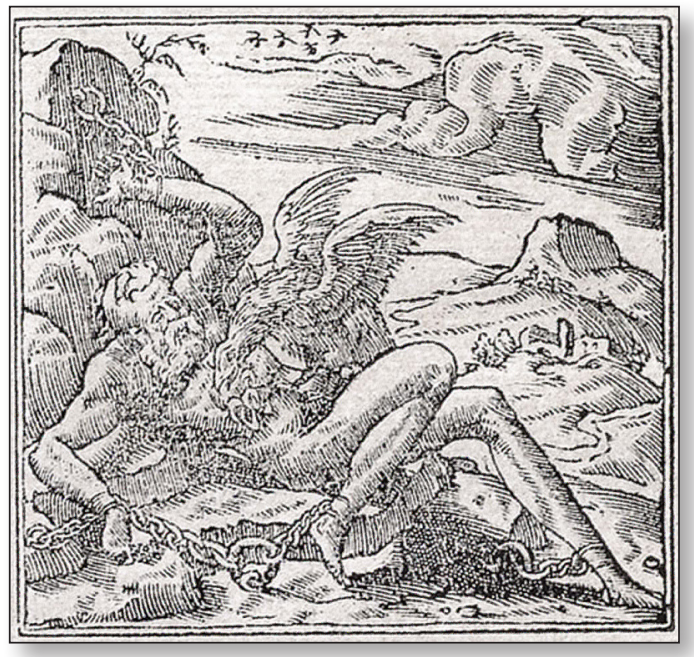

Fig. 6. Andrea Alciato, Los emblemas de Alciato. Emblema "Que con cuydado se acança la scineçia".

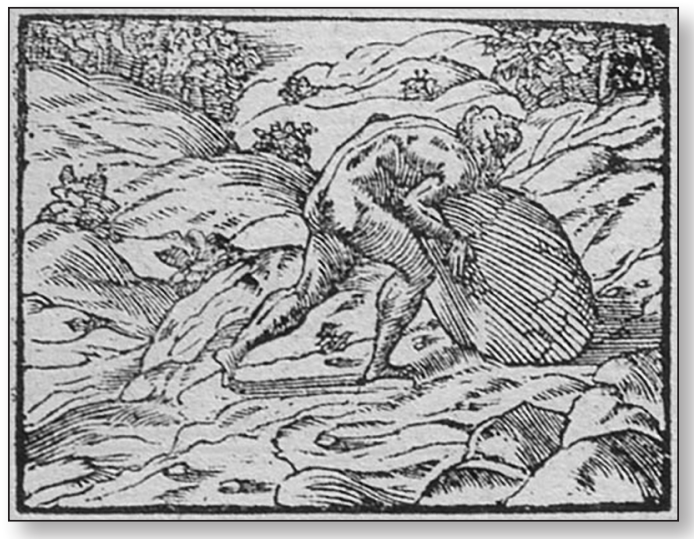

Fig. 7. Barthélmy Aneau, Picta poesis. Emblema «Interminabilis Humanae Vitae Labor».

de acuerdo con su propósito y su audiencia. En ese contexto, las imágenes que se encuentran dispuestas en las paredes, constituyen las piedras de toque del discurso, pero no el discurso propiamente dicho. Las imágenes están sujetas a ser interpretadas y organizadas para ser significativas. Cabe mencionar la distinción aristotélica entre la memoria y el recuerdo, ya que a través de ella se introduce un dinamismo discursivo en la noción de memoria que no se encuentra necesariamente entre las fuentes clásicas. Para Aristóteles, la memoria es un estado o afección ubicado en el alma que pertenece a la esfera de la imaginación (4445). Esta memoria y «aún la memoria de los objetos de pensamiento, no está desprovista de una imagen o pintura mental» (45). El recuerdo, por otra parte, hace uso de las imágenes de la memoria para ponerlas en función de un pensamiento discursivo que no es estático, sino que está provisto de un dinamismo propio de las facultades de la razón y el entendimiento. Cuando el hombre recuerda, dice Aristóteles, «infiere o deduce lo que él antes ha visto, ha oído o ha experimentado [...] y el proceso de recordar es una especie de búsqueda» (capítulo II). El relato de Everardo pone en entredicho la idea de que los sistemas de memoria artificial son simplemente técnicas mentales del recuerdo, empleados para impresionar e idealmente persuadir a la audiencia. En él, la memoria es también una forma de pensamiento, una reflexión en la que se comunica, se cuenta, se describe, se interpreta el pasado y se reflexiona sobre el presente.

\section{CONCLUSIÓN}

El relato intercalado de Everardo proporciona un contexto para examinar características retóricas y dialécticas de la memoria a través de la inserción de un programa emblemático. Si bien los aspectos retóricos de la memoria se encuentran por lo general asociados con prácticas de memorización que subrayan el uso de trasfondos e imágenes, los aspectos dialécticos se refieren a métodos de razonamiento y entendimiento que pretenden llegar, al menos en teoría, a la esencia de las cosas. Aunque ambos procesos podrían ser entendidos como procesos antitéticos, sugiero que el relato de Everardo combina de manera exitosa la memoria retórica y la dialéctica por medio de dos voces narrativas claramente diferenciadas. La 
primera es la voz del narrador omnipresente que suple la descripción de la celda en que se encuentran las imágenes. Esta narrativa inicial constituye el mapa verbal y visual que guía la narración del caballero pero que no la limita. La segunda es la voz misma de Everardo, el narrador en primera persona que saca a la luz el potencial mnemónico e interpretativo de las representaciones emblemáticas para reflexionar sobre la historia de su vida. Su relato refleja una capacidad discursiva, una manera de reflexionar sobre su pasado y su condición presente, en donde la relación entre los elementos icónicos y los lingüísticos de la historia es esencial.

\section{BIBLIOGRAFÍA}

Alciato, A. [2003]. Los emblemas de Alciato traducidos en rimas españolas Lyon 1549 , Palma de Mallorca, José J. de Olañeta.

Aneau, B. [1552]. Picta poesis, Lyons, Macé Bonhomme <http://www.emblems.arts. gla.ac.uk/french/books.php> 15-12-13.

Aristóteles [1966]. Del sentido y lo sensible. De la memoria y el recuerdo, Madrid, Aguilar, $<$ http://biblio3.url.edu.gt/Libros/2011/ del_sentido.pdf > 09-12-03.

Avalle-Arce, J.B. [2004]. "Sentido y género de El peregrino en su patria», en X. Tubau (ed.), Lope en 1604, Lérida, Milenio, 6178.

- [1973]. "Edición, introducción y notas», en El peregrino en su patria de Lope de Vega, Madrid, Castalia

Bernat Vistarini, A. y Cull, J. T. [1999]. Enciclopedia de Emblemas Españoles Ilustrados, Madrid, Akal.

Carruthers M. [1998]. The Craft of Thought, New York, Cambridge UP.

Cervantes, M. De [1994]. Entremeses, Madrid, Cátedra.

Cicero [2007]. "On the Ideal Orator (De oratore)" y "Ad Herennium", en M. Rossington y A. Whitehead (eds.), Theories of
Memory, Baltimore, Johns Hopkins UP, 37-49.

Coustau, P. [1555]. Pegma, Lyons, Macé Bonhomme, <http://www.emblems.arts.gla. ac.uk/french/books.php> 16-12-13.

CHecA, J. [2002]. «El peregrino en su patria de Lope de Vega y la cultura simbólica del barroco", en R. Zafra y J.J. Azanza (eds.), Emblemata áurea, Madrid, Akal, 99-110.

DefFis de Calvo, E.I. [1993]. "Amor y emblemas en un relato de Lope de Vega», Hispanic Journal, 14.2, 21-28.

Dixon, V. [2008]. "Lope's Knowledge», en A. Samson y J. Thacker (eds.), A Companion to Lope de Vega, Woodbridge, Tamesis, 15-28.

EgIDo, A. [2004]. «Lugares e imágenes de la memoria en la literatura y en el arte", en De la mano de Artemia, Palma de Mallorca, José J. de Olañeta, 51-74.

GiULIANI, L. [2004]. «El prólogo, el catálogo y sus lectores: una perspectiva de las listas de 'El peregrino en su patria'», en X. Tubau (ed.), Lope en 1604, Lérida, Editorial Milenio, 123-136.

GONZÁLEz RoviRA, J. [2004]. «Estrategias narrativas en 'El peregrino en su patria'", en X. Tubau (ed.), Lope en 1604, Lérida, Milenio, 137-149.

Kossoff, R. H. [1974]. "El peregrino en su patria by Lope de Vega; Myron A. Peyton", Modern Philology, 71.3, 331-335. < http:// dx.doi.org/10.1086/390498>

LARA GARrido, J. [2004]. "El peregrino en su patria de Lope de Vega desde la poética del romance griego", en X. Tubau (ed.), Lope en 1604, Lérida, Milenio, 95-122.

McCready, W. T. [1957]. "Empresas in Lope de Vega's Works", Hispanic Review, XXV.2, 79-104. <http://dx.doi. org/10.2307/470654>

RichaRds, J. [2007]. "Classical and Early Modern Ideas of Memory", en M. RosSIngton y A. WhiteheAd (eds.), Theories of Memory, Baltimore, Johns Hopkins UP, 20-27. 
RIPA, C. [1603]. Iconologia, Roma, Appresso Lepido Facij, <http://bit.ly/JylC30> 1512-13.

Rodríguez De LA Flor, F. [2005]. "Matrix Retórica. Trayectorias de la mnemotecnia y presentimientos del mundo virtual en la cultura de la edad moderna española», en San José Lera, J. (ed.), Praestans labore Victor, Salamanca, Ediciones Universidad, 197-216.

SAAVEdRA FAJARDO, D. [1999]. Empresas políticas, S. López (ed.), Madrid, Cátedra.
SAmson, A. [2008]. «Life's Pilgrim: El peregrino en su patria», en A. SAmson y J. Thacker (eds.), A Companion to Lope de Vega, Woodbridge, Tamesis, 229-243.

Soto, H. DE [1983]. Emblemas moralizadas, C. Bravo-Villasante (ed.), Madrid, Fundación Universitaria Española.

Vega Carpio, L. de [1997]. El peregrino en su patria. D. McGrady. (ed.), Madrid, Biblioteca Castro.

Yates, F. [1966]. The Art of Memory, Chicago, UP. 